\title{
Author Spotlight: Joseph S. Frye
}

Joseph S. Frye ${ }^{1}$

Accepted: 17 November 2020 / Published online: 12 January 2021

(c) Springer Science+Business Media, LLC, part of Springer Nature 2021

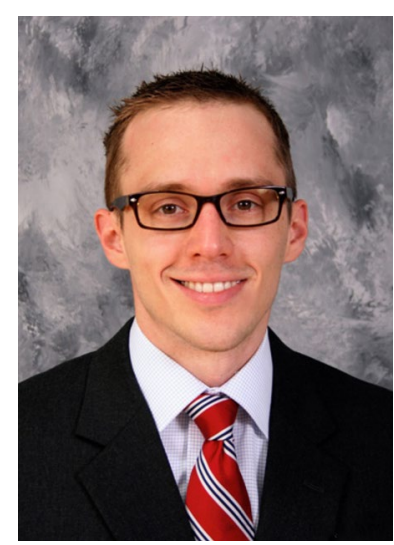

He completed residency at Cedars-Sinai Medical Center after obtaining his medical degree from the University of Missouri. After fellowship training in Gastrointestinal and Hepatobiliary Pathology at Stanford University, he intends to continue his career in academic medicine focusing on clinicopathologic correlations as well as trainee mentorship and education.

Publisher's Note Springer Nature remains neutral with regard to jurisdictional claims in published maps and institutional affiliations. 